\title{
OBSERVATIONS ON THE MECHANISM OF PROLONGATION OF PSEUDOPREGNANCY IN THE RAT FOLLOWING TRANSECTION OF THE UTERINE HORNS
}

\author{
J. D. O'SHEA \\ Department of Veterinary Preclinical Sciences, \\ University of Melbourne, Victoria, Australia
}

(Received 30th December 1970)

\begin{abstract}
Summary. Transection of the uterine horns near to their cervical ends (posterior uterine section) led to a prolongation of pseudopregnancy from $13 \cdot 1 \pm 0 \cdot 16$ (control) to $14 \cdot 9 \pm 0.24$ days $(P<0.001)$. This was significantly greater than the prolongation following transection of the uterine horns one third of the way from the uterotubal junction to the uterine bifurcation $(14 \cdot 0 \pm 0 \cdot 16$ days, $P<0 \cdot 01)$.

When unilateral ovariectomy was accompanied by contralateral posterior uterine section, the prolongation of pseudopregnancy $(14.5 \pm$ 0.20 days, control $12 \cdot 8 \pm 0.25$ days, $P<0.001$ ) was greater than when accompanied by ipsilateral posterior uterine section (13.7 \pm 0.20 days, $P<0.02)$.

These results indicate a quantitative and a unilateral component in the effects of uterine section, and support the hypothesis that prolongation of pseudopregnancy following posterior uterine section is brought about by the same mechanism as that following hysterectomy.
\end{abstract}

\section{INTRODUCTION}

It was shown that pseudopregnancy in rats is prolonged following surgical separation of the uterine horns from their cervical attachments (O'Shea, 1970). The mechanism involved was not determined, although an interference with normal uterine luteolytic activity was considered possible.

The concept that release of a luteolytic substance by the uterus plays an important rôle in limiting the life-span of the corpus luteum in many species of mammal has now gained wide acceptance (reviews by Schomberg, 1969; Rowson, 1970). However, the postulated luteolysin has not been identified with certainty, and no direct means is available to quantify its production or release. Hence, the effects of section of the uterus on uterine luteolytic activity cannot be measured directly. An indirect approach to determine whether the effects of uterine section parallel those of hysterectomy is, however, possible.

Anderson, Melampy \& Chen (1966) have shown that the degree of lengthening of pseudopregnancy in rats following hysterectomy is dependent upon the quantity of uterine tissue removed. Furthermore, a local, unilateral effect of 
hysterectomy has been demonstrated in the rat, in that removal of one uterine horn primarily affects the ipsilateral ovary (Barley, Butcher \& Inskeep, 1966).

If the mechanism which leads to lengthening of pseudopregnancy following uterine section is the same as that involved following hysterectomy, it could be predicted that both a quantitative and a local effect would be demonstrable following uterine section. This paper describes experiments which confirm these predictions.

\section{MATERIALS AND METHODS}

Female Hooded Wistar rats were used in two experiments. In both experiments, oestrous cycles and the duration of pseudopregnancy were studied by daily vaginal smears. Smears were taken daily for at least a week before operation and any rats which did not cycle normally (cycles between 4 and 6 days being regarded as normal) were discarded.

All operations were performed under ether anaesthesia on the 1st dioestrous day of a cycle. All rats were aged 9 to 10 weeks at the time of operation.

Pseudopregnancy was induced by sterile mating with vasectomized male rats. Mating was not permitted until after the completion of at least one normal postoperative oestrous cycle. The first day of an oestrous vaginal smear was designated as Day 0 , and the termination of pseudopregnancy was recognized by the return of vaginal oestrus. All rats were destroyed on the 1st subsequent day of dioestrus.

The procedure of uterine section was performed without interruption of the uterine blood vessels, which run through the broad ligament alongside the uterine horns (Text-figs. 1 and 2). Before sectioning with a scalpel, each uterine horn was clamped by artery forceps immediately above and below the site of section. The uterine horns were not ligated.

The procedure of left ovariectomy involved removal of the ovary and Fallopian tube. Section at the uterotubal junction was performed without ligation or clamping. In removal of the ovary, the ovarian branches of the utero-ovarian vessels were clamped and ligated. The utero-ovarian vessels, and their anastomoses with the uterine vessels, were left intact.

\section{Quantitative effect on the duration of pseudopregnancy}

The duration of a single pseudopregnancy cycle was recorded in rats in each of three groups: (1) control group: normal intact rats; (2) anterior uterine section group: uterine section was performed bilaterally at a point approximately one third of the way from the uterotubal junction to the uterine bifurcation (Textfig. $1, I)$; (3) posterior uterine section group: bilateral uterine section was performed just anterior to the uterine bifurcation (Text-fig. 1, II).

\section{Unilateral effect on the duration of pseudopregnancy}

The duration of a single pseudopregnancy cycle was recorded in rats in each of three groups: (a) left ovariectomy group: this group served as a control (Textfig. 2a); (b) left ovariectomy and left posterior uterine section group (Text-fig. 2b) ; (c) left ovariectomy and right posterior uterine section group (Text-fig. 2c). 


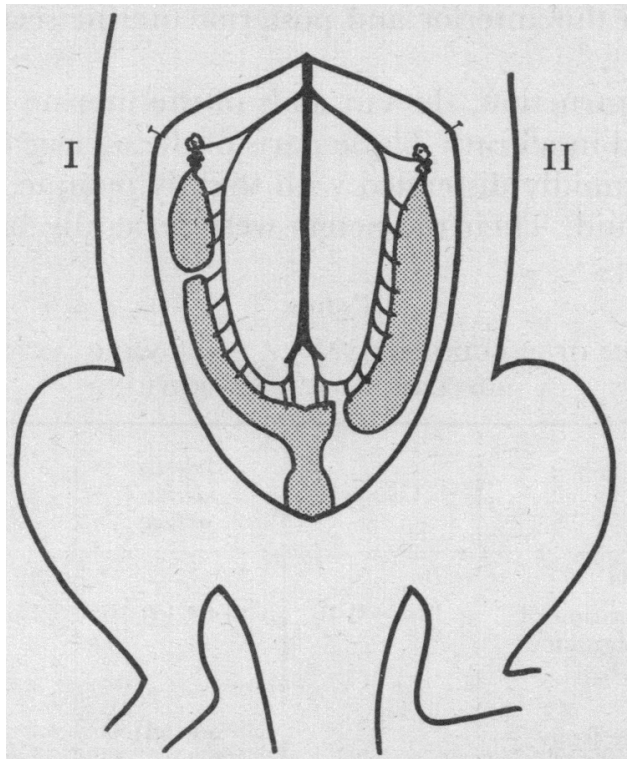

TEXT-FIG. 1. Diagrammatic representation of the operations of anterior uterine section (I) and posterior uterine section (II).

\section{RESULTS}

\section{Quantitative effect on the duration of pseudopregnancy}

The mean duration of pseudopregnancy in each of the three groups is shown in Table 1.

Both experimental groups showed a significant increase in the mean duration of pseudopregnancy. This increase was of 0.9 days in the anterior uterine section group and 1.8 days in the posterior uterine section group. The difference
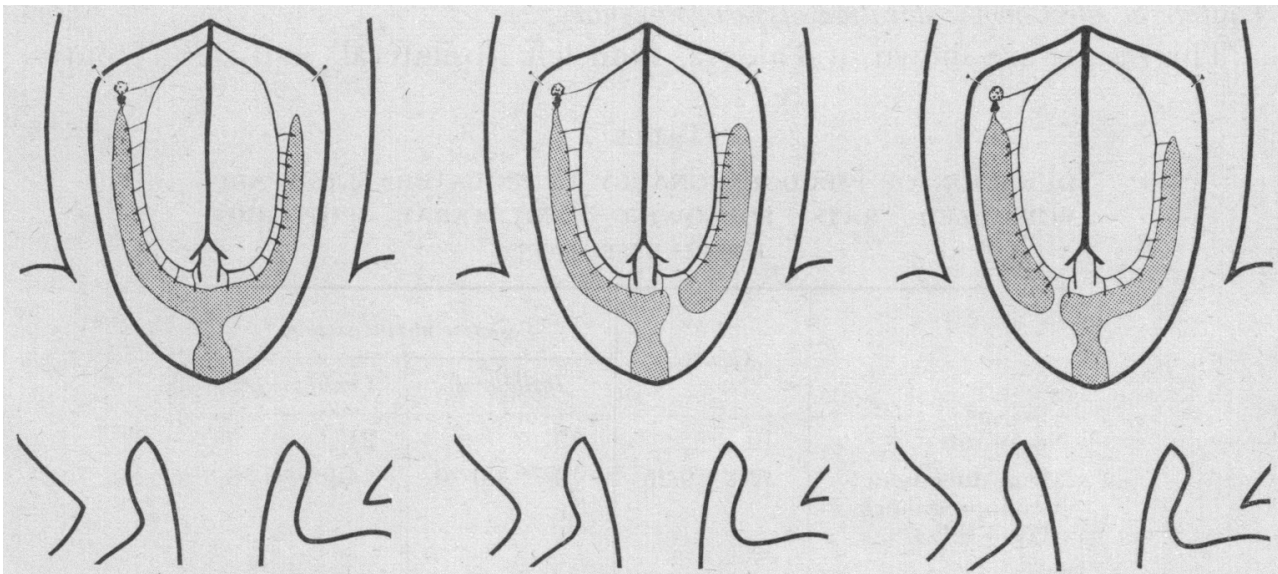

(b)
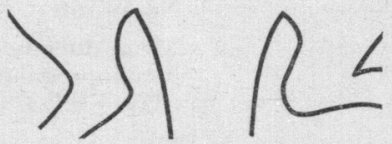

(a)

(c)

TEXT-pIG. 2. Diagrammatic representations of three experimental groups used to study the unilateral effect of posterior uterine section. (a) Left ovariectomy; (b) left ovariectomy and left posterior uterine section; (c) left ovariectomy and right posterior uterine section. 
of 0.9 days between the anterior and posterior uterine section groups was also significant $(P<0 \cdot 01)$.

At the time of destruction, the cut ends of the uterine horns were found to be completely sealed in all rats. Those parts of the uterine horns anterior to the site of section were mildly distended with slightly opaque, colourless or faintly yellowish, watery fluid. Their diameters were generally between 3 and $5 \mathrm{~mm}$

TABLE 1

DURATION OF PSEUDOPREGNANCY FOLLOWING ANTERIOR OR POSTERIOR UTERINE SEGTION

\begin{tabular}{l|l|l|l}
\hline & \multicolumn{1}{|c|}{ Control } & \multicolumn{1}{|c}{$\begin{array}{c}\text { Anterior } \\
\text { uterine } \\
\text { section }\end{array}$} & $\begin{array}{c}\text { Posterior } \\
\text { uterine } \\
\text { section }\end{array}$ \\
\hline $\begin{array}{l}\text { No. of rats } \\
\begin{array}{l}\text { Mean duration of } \\
\text { pseudopregnancy } \\
\text { (days } \pm \text { S.E.) }\end{array}\end{array}$ & $13 \cdot 1 \pm 0 \cdot 16$ & 35 & 36 \\
$\begin{array}{l}P \\
\text { (difference from } \\
\text { control) }\end{array}$ & $14 \cdot 0 * \pm 0 \cdot 16$ & $14 \cdot 9 * \pm 0.24$ \\
\hline
\end{tabular}

* Difference $P<0.01$.

(rarely up to $6 \mathrm{~mm}$ ) compared to approximately $2 \mathrm{~mm}$ in control rats and in the posterior parts of the uterine horns in rats in the anterior uterine section group.

One rat in which a unilateral pyometra was found at autopsy was excluded from consideration in the results. In three other rats in the posterior uterine section group, the uterine fluid was faintly or deeply brown coloured, but proved sterile on cultural examination. These rats were included in the results.

\section{Unilateral effect on the duration of pseudopregnancy}

The results are shown in Table 2. Both left (ipsilateral) and right (contra-

TABLE 2

DURATION OF PSEUDOPREGNANGY IN UNILATERALLY OVARIECTOMIZED RATS FOLLOWING UNILATERAL POSTERIOR UTERINE SECTION

\begin{tabular}{l|l|l|l}
\hline & \multirow{2}{*}{ Control } & \multicolumn{2}{|c}{ Posterior uterine section } \\
\cline { 2 - 3 } & & \multicolumn{1}{|c}{ Ipsilateral } & Contralateral \\
\hline $\begin{array}{l}\text { No. of rats } \\
\begin{array}{l}\text { Mean duration of } \\
\text { pseudopregnancy } \\
\text { (days } \pm \text { S.E.) }\end{array}\end{array}$ & 10 & 19 & 21 \\
$\begin{array}{l}P \\
\text { (difference from } \\
\text { control) }\end{array}$ & & $13 \cdot 7^{*} \pm 0.20$ & $14 \cdot 5^{*} \pm 0.28$ \\
\hline
\end{tabular}

* Difference $P<0.02$. 
lateral) posterior uterine section resulted in a significant increase in the duration of pseudopregnancy relative to the control group, of 0.9 and 1.7 days respectively. The difference of 0.8 days between the ipsilateral and contralateral groups was also significant $(P<0.02)$.

At autopsy, the sectioned horns showed a similar degree of distension with fluid to those of the posterior uterine section group in the previous experiment. The unsectioned horns, and those of rats in the control group, were normal in appearance. No instances of pyometra or brown staining of the uterine fluid were seen.

\section{DISGUSSION}

These experiments provide evidence that in uterine section, as in hysterectomy, both a quantitative and a local component are involved in the mechanism leading to the prolongation of pseudopregnancy. The site of section of the uterus significantly affected the duration of subsequent pseudopregnancy in such a way that a longer pseudopregnancy resulted when the uterine horns were divided near to their posterior ends. This suggests a quantitative effect dependent on the amount of uterine tissue situated anterior to the site of section. Ligation and section of the Fallopian tubes is without effect on the duration of pseudopregnancy in the rat (Barley et al., 1966). The difference between the effects of ipsilateral and contralateral uterine section in unilaterally ovariectomized rats is indicative of a local component. In this experiment, the small but significant increase in the duration of pseudopregnancy in the ipsilateral uterine section group suggests the possibility of an additional systemic component.

Further evidence of a parallel between the effects of hysterectomy and of section of the uterine horns is provided by observations that neither procedure significantly alters the duration of the normal short oestrous cycle in rats. Apart from a variable extension of the cycle during which the operation is performed, hysterectomy is without effect on the oestrous cycle (Long \& Evans, 1922; Bradbury, Brown \& Gray, 1950). Similarly, neither posterior uterine section (O'Shea, 1971), nor ligation of the uterus leading to accumulation of fluid in the lumen (Perrine, 1967), affect the duration of subsequent oestrous cycles.

The available data thus support the hypothesis that the effects of section of the uterus on pseudopregnancy in rats are mediated by the same mechanism as the effects of hysterectomy. It is, therefore, likely that section of the uterus under the conditions of these experiments interferes in some way with the production or release of the uterine luteolysin. However, it would appear that this interference is incomplete: the duration of pseudopregnancy following hysterectomy is of the order of 18 to 25 days (Anderson, Bland \& Melampy, 1969), which is considerably greater than that observed here after posterior uterine section.

In view of the quantitative relationship between the degree of prolongation of pseudopregnancy and the site of uterine section, it would appear that the factor most likely to have been responsible for prolongation of pseudopregnancy 
was the abnormal retention of secretion in those parts of the uterine horns denied their normal drainage. Experimental proof of this is, however, lacking and it has been reported that ligation of the uterine horns in the guinea-pig, leading to the accumulation of fluid in the uterine lumen, is associated with a shortening of subsequent oestrous cycles (Ginther, 1969). In other species, there is little clear evidence as to the effects of retention of uterine secretion on the life-span of corpora lutea. Hawk (1968) and Anderson et al. (1969) have reviewed reported data on the effects of introducing foreign materials into the uterine lumen in many species. In general, these data indicate that inert materials produce either a shortening of luteal life-span or are without effect on the corpus luteum. Lengthening of the luteal phase has generally been observed only when the nature of the foreign material is such as severely to damage or destroy the endometrium (Anderson, Butcher \& Melampy, 1961; Butcher, Chu \& Melampy, 1962).

\section{AGKNOWLEDGMENTS}

The expert assistance of Mr David Austin and Miss Irene Kerry is gratefully acknowledged. Rats were kindly donated by the CSIRO Division of Animal Health.

This work was supported by a grant from the Melbourne University Veterinary Research Fund.

\section{REFERENCES}

Anderson, L. L., BLAND, K. P. \& Melampy, R. M. (1969) Comparative aspects of uterine-luteal relationships. Recent Prog. Horm. Res. 25, 57.

Anderson, L. L., Butcher, R. L. \& Melampy, R. M. (1961) Subtotal hysterectomy and ovarian function in gilts. Endocrinology, 69, 571.

Anderson, L. L., Melampy, R. M. \& Chen, C. L. (1966) The uterus and ovarian activity in the pseudopregnant rat. Anat. Rec. 154, 309.

BARLEY, D. A., BUTCHER, R. L. \& INSKEEP, E. K. (1966) Local nature of utero-ovarian relationships in the pseudopregnant rat. Endocrinology, 79, 119.

Bradbury, J. T., Brown, W. E. \& Gray, L. A. (1950) Maintenance of the corpus luteum and physiologic actions of progesterone. Recent Prog. Horm. Res. 5, 151.

Butcher, R. L., Chu, K. Y. \& Melampy, R. M. (1962) Utero-ovarian relationships in the guinea pig. Endocrinology, 71, 810.

GinTHER, O. J. (1969) Effect of uterine ligation on ovaries and uterus in guinea pigs. Am. F. vet. Res. 30, 2215.

Hawk, H. W. (1968) Effect of intra-uterine devices on corpus luteum function. F. Anim. Sci. 27, Suppl. 1, 119.

Long, J. A. \& Evans, H. M. (1922) The oestrous cycle in the rat and its associated phenomena. Mem. Univ. Calif. 6, 1.

O'SHEA, J. D. (1970) Increased duration of pseudopregnancy associated with uterine distension in the rat. F. Reprod. Fert. 23, 229.

O'ShEA, J. D. (1971) Duration of the oestrous cycle and pseudopregnancy following uterine transection in rats. (Abstract). F. Reprod. Fert. 24, 143.

Perrine, J. W. (1967) The formation and composition of rat uterine luminal fluid. Diss. Abstr. 27, 2854B.

Rowson, L. E. A. (1970) The evidence for luteolysin. Br. med. Bull. 26, 14.

Schomberg, D. W. (1969) The concept of a uterine luteolytic hormone. In: The Gonads. Ed. K. W. McKerns. North Holland Publishing Co., Amsterdam. 